Jasmina Bajo

Kulturni centar „Nikola Đurković “ Gradska biblioteka i čitaonica Kotor
УДК 004.065:027.022

дОИ https://doi.org/10.18485/

melissa.2016.15.1.ch16

\title{
DIGITALNE TEHNOLOGIJE KAO SREDSTVO PRETVARANJA JAVNE BIBLIOTEKE U CENTAR LOKALNE ZAJEDNICE
}

\begin{abstract}
Sažetak
U ovom radu ukazaćemo na to kako se pod uticajem digitalnih tehnologija, kao neminovnosti novog doba, tradicionalna uloga javne biblioteke polako mijenja. Nove okolnosti nameću nove potrebe i zahtjeve korisnika, kojima se biblioteke moraju prilagođavati. Savremena javna biblioteka treba da predstavlja mjesto susreta, gdje se korisnici u ugodnom i kreativnom prostoru okupljaju, uče, razmjenjuju mišljenja i znanja, stvaraju... Na taj način biblioteke postaju neformalni centri znanja. Svoj profesionalni kapacitet one mogu jačati u bliskoj saradnji s partnerima u javnom i privatnom sektoru, doprinoseći podizanju kvaliteta života u lokalnoj zajednici. Pomenute inovacije postižu se brojnim savremenim bibliotečkim servisima, od kojih ćemo predstaviti: e-Uprava servis, Informacije o zdravstvenoj zaštiti, Crowdsourcing digitalnog časopisa, Media Lab i Makerspace.
\end{abstract}

Ključne reči: Javna biblioteka, bibliotekari, bibliotečki servisi, lokalna zajednica, e-Uprava servis, informacije o zdravstvenoj zaštiti, Crowdsourcing, digitalni časopis, Media Lab, Makerspace

Uvijek kažu da vrijeme mijenja stvari, no zapravo ih morate promijeniti sami.

Endi Vorhol

\section{Javne biblioteke u svijetu digitalnih tehnologija}

Svijet je doživio gotovo potpuni preobražaj pod dejstvom digitalnih tehnologija, tako da danas možemo reći da živimo u društvu prezasićenom 
digitalnom tehnologijom. Čarli Gir, direktor Instituta za istraživanje kulture pri Univerzitetu Lankaster, ističe da „,istovremeni razvoj nauke, medija i kapitala pod pokroviteljstvom digitalnih tehnologija stvara neku vrstu efekta ubrzanog kretanja napred, gde se čini da se sve odvija brzo i da se dramatične promene događaju u izuzetno kratkom vremenu" (Gir 2011: 16). Međutim, ove promjene nisu rezultat samo razvoja digitalnih tehnologija već i opšte pojave u kulturi, filozofiji, sociologiji, uopšte u društvenom životu.

Niz tehnoloških i društvenih promjena utiču na to da se tradicionalna uloga javne biblioteke polako mijenja, jer su one usmjerene prema svim slojevima društva bez obzira na razlike i predstavljaju „najširu i najdemokratskiju javnu ustanovu“ (Nebesny, Švob 2002). „Ovo su zbunjujuća vremena za sve koji imaju veze s bibliotekama“ (Brofi 2005: 10), rekao je Piter Brofi. Pesimistička predviđanja o položaju javnih biblioteka u savremenom društvu govore da su javne biblioteke zastarjele, prevaziđene, anahrone i nevidljive. Digitalne tehnologije, kao neminovnost savremenog doba, nameću i nove zahtjeve, a javne biblioteke ih moraju razumjeti i prilagoditi se novim zahtjevima svojih korisnika, poštujući navode Uneskovog Manifesta za javne biblioteke u kojem stoji da: Javna biblioteka, lokalna kapija znanja, pruža osnovne uslove za doživotno učenje, nezavisno donošenje odluka i kulturni razvoj pojedinaca i društvenih grupa. ${ }^{1}$ Vesna Injac Malbaša u knjizi E-biblioteka zaključuje „da ukoliko biblioteke ne žele da ostanu prazne, one će svakako morati da prihvate izazove novog umreženog i digitalnog sveta [...] da više poštuju svoje korisnike, njihove potrebe, zahteve $\mathrm{i}$ mišljenja o pruženim uslugama“ (Injac Malbaša 2016: 321).

\section{Javne biblioteke kao neformalni centri znanja}

Imajući rečeno u vidu, osvrnućemo se na određene inovacije u javnim bibliotekama, a zatim predstaviti neke od savremenih bibliotečkih servisa, zahvaljujući kojima javna biblioteka može da postane centar lokalne zajednice.

Ciljna grupa javne biblioteke su upravo članovi lokalne zajednice, a jedan od njenih zadataka je zadovoljenje potreba korisnika. Korisnici nisu

1 Međunarodni bibliotečki manifesti IFLA / UNESCO (2014) 
više pasivni potrošači medija, već sve više aktivni stvaraoci. Poznavanje potreba korisnika i uvođenje servisa koji će odgovoriti tim potrebama od presudnog su značaja za opstanak i funkcionisanje javne biblioteke. Potrebe savremenih korisnika više se ne zadovoljavaju samo prostim pozajmljivanjem knjiga ili čitanjem dnevnih novina, korisnici više nisu obični potrošači informacija (Injac Malbaša 2016: 323). Savremena javna biblioteka predstavlja mjesto susreta, gdje se oni u ugodnom i kreativnom prostoru okupljaju, uče, razmjenjuju mišljenja i znanja, stvaraju... Na ovaj način biblioteke doprinose podizanju kvaliteta života u lokalnoj zajednici.

Da bi se ispunio ovaj cilj, u biblioteci moraju raditi kreativni, analitični, komunikativni ljudi, koji su u stanju da se povežu s lokalnom zajednicom, prepoznaju njene potrebe i u saradnji s korisnicima razvijaju one servise koji su najpotrebniji na tom području i koji će podići kvalitet života u lokalnoj zajednici.

Javne biblioteke mogu postati neformalni centri znanja, jačajući svoj profesionalni kapacitet u bliskoj saradnji s partnerima u javnom i privatnom sektoru. Samim tim se poštuje demokratski princip slobodnog pristupa za sve, na kojem treba da počiva rad svake javne biblioteke.

Dejvid Lejnks kaže da ako biblioteke imaju budućnost, a on tvrdi da imaju, onda održivost nije okretanje građi, zgradama, itd., već učenju, znanju i socijalnoj akciji. Što znači da je novi identitet bibliotekara u 21. vijeku prije svega određen upravljanjem saznajno-komunikacionim procesima u novom kontekstu, te ga je potrebno redefinisati u skladu s očekivanjima korisnika digitalnog doba. Promjena će ipak doći samo tamo gdje se nađu pojedinci koji su spremni vještine informacijske, digitalne, medijske pismenosti staviti u službu javnog interesa i javnog dobra (Hiber 2015).

\section{Savremeni bibliotečki servisi}

Među brojnim savremenim bibliotečkim servisima za ovu priliku izdvojićemo: e-Government (e-Uprava servis), Health care information (Informacije o zdravstvenoj zaštiti), Crouwdsourcing digitalnog časopisa, Media Lab i Makerspace. 


\section{Servis e-UPRAVA}

Javne biblioteke treba da posredstvom digitalnih tehnologija svojim korisnicima omoguće dobijanje kvalitetnih informacija, koje će doprinijeti društvenom, ekonomskom i demokratskom razvoju zajednice. U tom cilju servis e-Uprava obezbjeđuje korisnicima pristup zvaničnim i vladinim informacijama, kao i tumačenje administrativnih i poslovnih informacija. Korisnici sve više pokazuju potrebu da se odgovori na zahtjeve poput podnošenja molbe za posao ili izdavanja ličnih dokumenata, predaje godišnjih poreskih izvještaja, pretraživanja informacija o obrazovnim ili preduzetničkim grantovima, prijavljivanja kriminalnih djela onlajn, pronalaženja podrške za poboljšavanje lokalne infrastrukture ili ostvarivanja građanskih prava, pristupa vladinim službama i predstavnicima.

Odgovarajući na ove zahtjeve, Centralna biblioteka „M. L. Kropyvnytskyi“, iz ukrajinskog grada Nikolajeva, 2012. godine otvorila je 18 građanskih servisnih centara koji uspješno izlaze u susret potrebi građana da ostvare interakciju sa zvaničnim institucijama i pronađu efikasna rješenja za svoju zajednicu. Za samo osam mjeseci od pokretanja ovog servisa u oktobru 2012. godine više od 2.100 građana ga je koristilo za obuku i upotrebu informacione i komunikacione tehnologije, za interakciju s vladinim zvaničnicima i za pristup e-upravi.

http://www.eifl.net/eifl-in-action/open-government-innovation-award-1

http://bibliomist.org/en/about-bibliomist/news-eng/746-public-libraries-empowering-citizens-to-interact-with-government

Informacije o zdravstvenoj zaštiti

Javna biblioteka „East Brunswick“ u Nju Džersiju, SAD, pokrenula je servis Samo za zdravlje (Just For The Health Of It), bibliotečku inicijativu o zdravstvenoj zaštiti koja uključuje onlajn portal preko koga korisnici, na sedam jezika, imaju pristup provjerenim i pouzdanim informacijama vezanim za zdravlje, socijalnu zaštitu i zdravstveno osiguranje.

Inicijativa Samo za zdravlje, kojoj pristupa jedna po jedna javna biblioteka, dio je velikog napora američkih biblioteka ka poboljšanju zdravstvene pismenosti. 
Tim bibliotekara zaduženih za zahtjeve korisnika koji se tiču informacija o zdravlju, korisniku će, uz poštovanje i razumijevanje, uvijek pomoći da pronađe kvalitetne i pouzdane informacije na osnovu kojih može biti spremniji za razgovor sa svojim ljekarom i postići bolje rezultate u liječenju.

Mnogi bibliotekari u javnim bibliotekama nemaju neophodno medicinsko obrazovanje, ali su svakodnevno suočeni sa situacijom da korisnici traže odgovore na pitanja vezana za zdravlje. Prva stvar koju bibliotekar kaže korisniku koji traži informacije u vezi sa zdravljem jeste da ne pretražuje svoje simptome na Guglu. Umjesto toga, bibliotekar pomaže korisniku u potrazi za odgovorima vezanim za njegovo zdravstveno stanje pretražujući informacije na pouzdanom i besplatnom vebsajtu Medline-Plus (https://medlineplus.gov).

Prema istraživanju National Library of Medicine (NLM) preko 90 miliona odraslih Amerikanaca imaju slabu zdravstvenu pismenost, što znači da ne znaju kako mogu da dobiju potrebne informacije o zdravlju i zdravstvenim servisima i te informacije razumiju. Zadatak javnih biblioteka je da promoviše i ovu vrstu pismenosti. SWICK-PL

http://seniorspaces.pbworks.com/w/page/15791752/EAST-BRUN-

http://www.wellinks.org/

\section{Crowdsourcing digitalnog časopisa}

Crowdsourcing je noviji termin u bibliotečkoj djelatnosti. Vesna Injac Malbaša mu je posvetila cijelo poglavlje u knjizi E-biblioteka. Objašnjava ga kao „kombinaciju napora grupe ljudi, obično volontera, u nekom poslu u kojem svaki pojedinac daje mali doprinos u cilju ostvarivanja nekog većeg rezultata i grupnog cilja“ (Injac Malbaša 2016: 326). Bibliotekari koji svoje korisnike angažuju kao saradnike u različitim bibliotečkim projektima provode crowdsourcing. Ista autorka ističe da uspješan crowdsourcing podrazumijeva sljedeće karakteristike: „postoji jasno definisana masa pojedinaca, postoji zadatak $s$ jasnim ciljem, korist stečena od mase je evidentna, pokretač zahteva je jasno identifikovan, kompenzacija za pojedince iz mase je utvrđena, to je onlajn proces participativnog tipa, koristi otvoren poziv različitog opsega i sve se odvija preko interneta“ (Injac Malbaša 2016: 335). 
Jedan od uspješnih primjera crowdsourcing-a je onlajn Magazin Gradske knjižnice Rijeka, koji se oslanja na kreativnost studenata i mladih nezaposlenih Riječana. Magazin uređuje tim sastavljen od osam urednika volontera, dizajnera i lektora, a bazira se na sistemu slobodnog izbora sadržaja, koji omogućava korisnicima da kreiraju, objave i prikažu tekst i slike iz različitih računarskih uređaja. Časopis broji 68 redovnih saradnika i 2.000 posjetilaca dnevno. Gradska knjižnica Rijeka je dobila EIFL (Electronic Information for Libraries) nagradu za ovaj servis.

http://gkr.hr/Magazin

\section{Media Lab}

Media Lab servis u javnoj biblioteci predstavlja stimulativni višedimenzionalni prostor koji omogućava korisnicima pristup softverskoj i hardverskoj opremi za razvoj i uređivanje digitalnih sadržaja - kao što su video-zapisi, muzika, fotografije, e-knjige, vebsajtovi, animacije i drugo - ili konvertovanje starijih medija u digitalne formate. Ovaj prostor uglavnom se gradi u lako prilagodljivom enterijeru koji podstiče korisnikovu nezavisnost, kao i stvaranje i učenje u zajednici.

Specifične mogućnosti servisa Media Lab mogu uključivati video-montažu (Final Cut, iMovie), obrađivanje fotografija (Photoshop, IIIustrator, After Effects), obradu zvuka (Adobe Audition, Garageband), kreiranje sajtova (Dreamweaver, Flash) i osnove produkcije (MS Office, web browsers, Adobe Acrobat Pro).

Mnoge biblioteke su napravile i korak naprijed, omogućivši da se ovaj prostor koristi za kreiranje i obrađivanje digitalnih medija, a u isto vrijeme da promoviše učenje u zajednici (community learning).

Značajni primjeri su Media Lab u grčkim javnim bibliotekama, koje je razvio Future Library u saradnji s Guglom za dizajn prostora i obuku bibliotekara, s Gradskom bibliotekom Aarhus za evaluaciju predloga arhitekata i s Mozila fondacijom za dizajn Media Lab programa koji promovišu kreativnu upotrebu novih tehnologija.

Grčki Media Lab servisi sastoje se od tri glavna prostora:

1. Zvučno izlovani muzički studio za audio-video emitovanje opremljen računarom, video-kamerom, programima za video i foto obradu, 
muzičkim instrumentima, u kojem svako može snimiti video, stvoriti digitalnu priču, radio-spot ili čak i svoje vlastite pjesme.

2. Lounge ili foaje za učenje u zajednici (community learning) $\mathrm{s}$ kompjuterima, sofama, stolom, pokretnim stolovima, projektorima i interaktivnom tablom. Korisnici mogu napraviti svoje prezentacije, održavati sastanke ili jednostavno surfovati internetom s pristupom ekskluzivnom digitalnom sadržaju, a u isto vrijeme opuštati se u ugodnom i prijateljskom okruženju.

Tu se nude i razni programi kao što su kursevi fotografije, kineskog jezika, rad na računaru, predstavljanje knjiga i razgovora, večeri poezije, radionice pletenja, a isto tako svi - obično domaći izvođači - mogu održavati i koncerte koji su besplatni i otvoreni za javnost.

3. Brain Puls zvučno izlolovani prostor, idealan za glasne brainstorming sastanke,

gdje ljudi dolaze da bi projektovali i razrađivali svoje projekte ili samo sjedali i opustili se!

Izvanredan primjer Media Lab sistema je Biblioteka 10, Gradske biblioteke u Helsinkiju, koja promoviše muzičku kreativnost iznajmljivanjem opreme za digitalnu produkciju uz muzičke instrumente i pozornicu.

http://www.helmet.fi/en-US/Libraries_and_services/Library_10

Glavna ciljna grupa ovog bibliotečkog servisa je generacija Y, što znači da se radi o mladima rođenima tokom osamdesetih i ranih devedesetih godina, dok je glavni cilj pružiti tinejdžerima, studentima, profesionalcima, nezaposlenima i imigrantima mogućnosti za stvaranje, komunikaciju, inovaciju i učenje u biblioteci. Ono što Media Lab čini veoma moćnim servisom jeste da djeluje kao središte za kreativnost, saradnju, inovacije i učenje na temelju ideja, umjetnosti, kulture, prirodnih i humanističkih nauka.

\section{Makerspace}

Ovaj servis prije svega dokazuje da su biblioteke mjesto kreacije, razmišljanja, eksperimentisanja. Servis je usmjeren na generaciju za koju ne želimo da samo konzumira strane proizvode, već sama domišlja i ostva- 
ruje ideje (Benić 2015). Makerspace je izrastao iz maker kulture - pokreta posvećenog zanatstvu i pojedinačnoj proizvodnji nasuprot masovnoj produkciji i potrošnji.

Makerspace je prostor u kome se ljudi okupljaju da stvaraju i sarađuju, da dijele znanje i resurse, koristeći alatke od elektronskih do digitalnih medija, 3D štampanja i drugo, koje korisnici nemaju u svojim domovima. To su prostori za nove ideje i projekte po principu Uradi sam. Razlika između Makerspace-a i Media Lab-a je što su proizvodi kreirani u Makerspace-u uglavnom materijalne prirode, dok su proizvodi Media Lab-a uglavnom digitalni. U Makerspace-u djeca se okupljaju da prave Lego robote; tinejdžeri eksperimentišu, projektuju i stvaraju predmete koristeći računare, 3D printere i laser za rezanje; studenti inženjerstva prave nove projekte; odrasli kreiraju prototipove za proizvode malih preduzeća.

Pokret Makerspace se u SAD pojavio već u prvim godinama novog milenijuma, a u međuvremenu je stigao i do biblioteka. The Fayetteville Free Library iz Njujorka je prva biblioteka u Americi u kojoj je otvoren Makerspace. Direktorka razvoja transpismenosti ove biblioteke, Loren Smedli, izjavila je: „Narodne biblioteke postoje da omoguće slobodan i otvoren pristup informacijama, tehnologiji i idejama. Otvaranje Makerspace-a (mi ga zovemo fenomenalnom laboratorijom) u FFL će našoj zajednici omogućiti slobodan pristup novim tehnologijama koje mijenjaju svijet“ (McCue 2011).

Gradska biblioteka u Kelnu je 2013. bila prva biblioteka u Njemačkoj u kojoj je otvoren Makerspace. Osim 3D štampača i skenera, korisnicima danas stoje na raspolaganju ajpedi, klavijature, gitare, kao i upravljač za kontrolu muzičkog softvera. Korisnici tu mogu da digitalizuju gramofonske ploče, da komponuju na ajpedima i još mnogo toga. U Kelnu, Makerspace ima svoje čvrsto mjesto i odlično razrađenu korisničku mrežu. „Uloga biblioteke jeste da učestvuje u posredovanju i realizaciji raznih aktivnosti“, smatra direktorka kelnske biblioteke, Hanelor Fogt. „Ona nudi tehničku i prostornu infrastrukturu - a ljudi se uzajamno pomažu, prenoseći jedni drugima znanje" (Vogt 2015). Težište je, dakle, na umrežavanju, informacijama i edukaciji. Za Hanelor Fogt, jedna od ključnih tačaka je učenje u zajednici koje obuhvata nekoliko generacija. U kelnskom Makerspace-u učenice i učenici iz obližnje škole nude sljedeće kurseve: Komponovanje pomoću ajpeda, Kako da napravim svoj blog?, Digitalna obrada fotografije i Ubrzani 3D kurs za početnike. 
https://stadtbibliothekkoeln.wordpress.com/makerspace/

Krajnji cilj ovog servisa je produbljivanje interesa za nauku, tehnologiju i dizajn, tako što će se korisnicima omogućiti učenje kroz eksperimentisanje tako što će tehnologija biti dostupna široj javnosti, posebno djeci i mladima, zaposlenima i starijima koji često dolaze u biblioteku. Očekuje se da razvijanje ovog servisa ima značajan uticaj na lokalnu zajednicu. Partnerstva su ključni sastojak za razvoj uspješnog bibliotečkog Makerspace-a s postojećim resursima. Na primjer, javne biblioteke mogu sarađivati s malim lokalnim tehnološkim firmama na idejama i uvoditi u biblioteku Makerspace. Zauzvrat, tehnološke kompanije mogu koristiti bibliotečke prostore da se reklamiraju i postanu vidljive u zajednici. Takođe, volonteri mogu stručno pomoći bibliotekarima i korisnicima u savlađivanju vještine rukovanja novim uređajima.

\section{Zaključak}

Biblioteke su jedino mjesto gdje se novonastale informacione tehnologije mogu kombinovati s tradicionalnim izvorima učenja. One postaju prostor okrenut potrebama korisnika, bogat servisima koji podržavaju savremene modele učenja, predavanja, stvaranja i saradnje. Dok internet teži da izoluje ljude, biblioteka kao prostor radi upravo suprotno. Kao dinamičan prostor za učenje, koji kombinuje materijalne i digitalne formate, ona može ponovo postati mjesto glavne podrške napretku zajednice.

Biblioteka treba da bude živa veza između baštine prošlosti i zahtjeva modernog informacijskog društva budućnosti. Cilj je da biblioteka mijenja život ljudi nabolje, da bude živo srce grada i resurs za cijelu zajednicu.

\section{Literatura}

Anthony, C. A. (2014) Innovation in public libraries. Public libraries on line, 53 (1), Dostupno na: http://publiclibrariesonline.org/2014/02/innovation-in-publiclibraries/ [pristupljeno 18. 5. 2016]

Benić, K. Rijeka city library prepares children and youth high tech future, EIFL Blogs [on line]. 19 May 2015, dostupno na: http://www.eifl.net/blogs/rijeka-city-libraryprepares-children-and-youth-high-tech-future [pristupljeno 10. 8. 2016] 
Brofi, P. Biblioteke u dvadeset prvom veku: nove usluge za informaciono doba. Beograd: Clio, 2005.

Drotner, K. (2005) Library innovation of the knowledge society, Scandinavian Library Quarterly 38 (2), dostupno na: http://slq.nu/?article=library-innovation-for-theknowledge-society [pristupljeno 18. 5. 2016]

Gir, Č. Digitalna kultura. Beograd: Clio, 2011.

Grizl, A., Mur, P., Dezuani M., Astana S., Vilson, K., Banda F., Onuma Č. INFORMACIJSKA imedijska pismenost: smjernice za politiku i strategiju. Cetinje: NBCG „Đurđe Crnojević“, 2015.

Hiber, M. Probleme proizvodi nepoznavanje misije bibliotekarstva u 21. stoljeću. Oslobođenje, 2015, dostupno na http://www.oslobodjenje.ba/kun/tehnologija/ mario-hiber-probleme-proizvodi-nepoznavanje-misije-bibliotekarstva-u-21stoljecu/153193 [pristupljeno 7. 12. 2016]

Injac Malbaša, V. E-biblioteka. Beograd: Clio, 2016.

McCue, Tj. First public library to create a maker space. Forbes, 15 November 2011, dostupno na: http://www.forbes.com/sites/tjmccue/2011/11/15/first-publiclibrary-to-create-a-maker-space/\#63457ddb80da [pristupljeno 20. 5. 2016]

Međunarodni bibliotečki manifesti IFLA / UNESCO (2014), dostupno na http://nub.rs/ fileadmin/dokumenti/ostali dokumenti/Medjunarodni-bibliotecki-manifesti.pdf [pristupljeno 7. 12. 2016]

Nebesny, T., Švob M. „Izgradnja knjižne zbirke u narodnim knjižnicama“. Slobodan pristup informacijama u službi kulturnog razvitka: zbornik radova. Ur. Alemka Belan-Simić i Aleksandra Horvat. Zagreb: Hrvatsko knjižničarsko društvo, 2002.

Vogt, H. Stadtbibliothek Köln - Libraries in the Digital Age: Innovative Services and the Transformation of Space, 26 March 2015, dostupno na http://www.slideshare. net/acim asso/2015-metz-engl20150326 [pristupljeno 10. 8. 2016]

\section{Internet stranice}

http://bibliomist.org/en/about-bibliomist/news-eng/746-public-libraries-empoweringcitizens-to-interact-with-government [pristupljeno 10. 8. 2016]

http://www.eifl.net/eifl-in-action/open-government-innovation-award-1 [pristupljeno 10. 8. 2016]

http://gkr.hr/Lab [pristupljeno 11. 8. 2016]

http://gkr.hr/Magazin [pristupljeno 10. 8. 2016]

http://www.helmet.fi/en-US/Libraries_and services/Library_10 [pristupljeno 11. 8. 2016]

http://libkor.gr/vivliothiki/media-lab [pristupljeno 11. 8. 2016]

http://www.libver.gr/medialab/ [pristupljeno 11. 8. 2016]

http://seniorspaces.pbworks.com/w/page/15791752/EAST-BRUNSWICK-PL [pristupljeno 11. 8. 2016]

https://stadtbibliothekkoeln.wordpress.com/makerspace/ [pristupljeno 11. 8. 2016]

http://www.wellinks.org/ [pristupljeno 11. 8. 2016] 
Jasmina Bajo

\title{
PUBLIC LIBRARIES USE DIGITAL TECHNOLOGY TO REDEFINE THEIR ROLE IN COMMUNITIES BY BECOMING THEIR CENTER
}

\begin{abstract}
Summary
The purpose of this article is to present in which way, under the influence of digital technology, as necessity of modern era, the traditional role of Public library slowly begins to change. New circumstances have imposed new needs and new requests and Public Libraries have to understand them and adjust to the new requests of their users. Modern Public Library should represent a meeting place where users come together in comfortable and creative space, where they can learn, exchange opinions and knowledge, where they can create...Public Libraries in this way become informal learning centers. Public Libraries can improve their professional capacity in close cooperation with partners from public and private sector, contributing to raise quality of life in local community. Abovementioned innovations can be achieved with numerous modern library services and in this paper we will present the following: Makerspace, Media lab, e-Government service, Health care information, Crowdsourcing digital magazine.
\end{abstract}

Key words: Public library, Librarians, Library services, Local community, e-Government service, Health care information, Crowdsourcing, Digital magazine,Media lab, Makerspace. 